\title{
Periculosidade versus cidadania: os sentidos da atenção à crise nas práticas discursivas dos profissionais de um Centro de Atenção Psicossocial
}

\author{
I ${ }^{1}$ Janaína Quinzen Willrich, ${ }^{2}$ Luciane Prado Kantorski, ${ }^{3}$ Fabieli Gopinger \\ Chiavagatti, ${ }^{4}$ Jandro Moraes Cortes, ${ }^{5}$ Guilherme Weiss Pinheiro I
}

Resumo: A crise, considerada a expressão da doença psíquica, refere-se a situações em que, no curso do desenvolvimento de vida, ocorrem vivências conflitivas que geram rupturas com a realidade socialmente aceita e com os laços afetivos que sustentam a pessoa. Esta pesquisa objetiva conhecer os sentidos presentes nas práticas discursivas dos profissionais acerca da atenção à crise nos Centros de Atenção Psicossocial (CAPS). Caracteriza-se por uma abordagem qualitativa que utiliza a perspectiva teórica do Construcionismo Social. Os dados utilizados fazem parte do banco de dados da pesquisa Avaliação dos Centros de Atenção Psicossocial da Região Sul do Brasil (CAPSUL). No presente estudo, analisamos 27 entrevistas realizadas com profissionais do Centro de Atenção Psicossocial de Alegrete e três diários de campo com o registro de 390 horas de observação. A análise dos dados identificou sentidos - periculosidade e cidadania - que foram discutidos na busca de compreender sua influência na construção de práticas de atenção à crise.

> Palavras-chave: intervenção na crise; saúde mental; enfermagem psiquiátrica; produção de sentidos.

\author{
1 Universidade Federal de \\ Pelotas, Rio Grande do Sul \\ (UFPel). Endereço eletrônico: \\ janainaqwill@yahoo.com.br \\ 2 UFPel. Endereço eletrônico \\ kantorski@uol.com.br \\ ${ }^{3}$ UFPel. Endereço eletrônico: \\ fabichiavagatti@yahoo.com.br \\ ${ }^{4}$ UFPel. Endereço eletrônico \\ jandromcortes@hotmail.com \\ ${ }^{5}$ UFPel. Endereço eletrônico \\ gui_ewpinheiro@yahoo.com.br
}

Recebido em: 08/06/2010. Aprovado em: 01/11/2010. 
A loucura, que despertou inúmeras reações da sociedade nas diferentes épocas - desde a sua exaltação até sua submissão ao saber médico -, está intimamente ligada a sentidos e práticas de exclusão e segregação. A compreensão dos sentidos despertados pela loucura no contexto social e sua relação com a construção de práticas de violência e exclusão que marcaram a trajetória do louco no campo da psiquiatria, instigou, em alguns atores sociais, o desejo de iniciar um processo de desconstrução dos saberes e práticas manicomiais.

No âmbito nacional, esse processo desencadeou o movimento de reforma psiquiátrica, surgido na década de 70 , no qual as mudanças propostas se configuram como um novo paradigma de atenção em saúde mental, em que o cuidado ao indivíduo em sofrimento psíquico implica a necessidade de práticas e posturas permeadas pelo respeito, ética e responsabilidade. Neste sentido, a configuração das práticas em saúde mental orienta-se com base em fundamentos epistemológicos que se situam em ruptura ao paradigma hospitalocêntrico asilar, atribuindo um novo sentido social para a loucura e, para isso, instaurando o modelo de atenção psicossocial (COSTA-ROSA; LUZIO; YASUI, 2003).

Neste parâmetro de mudanças paradigmáticas, surge a questão da dificuldade da atenção à crise nos serviços substitutivos, pois concordamos que este é um dos aspectos mais difíceis e estratégicos no processo de reforma psiquiátrica (AMARANTE, 2007).

Quando nos referimos às crises psíquicas em saúde mental, estamos considerando o momento da vida em que o sofrimento é tão intenso que acaba por gerar uma desestruturação na vida psíquica, familiar e social do sujeito. Situações em que, no curso do desenvolvimento de vida, ocorrem vivências conflitivas que acarretam uma ruptura com a realidade socialmente aceita e com os laços afetivos que o sustentam como pessoa. A crise é a expressão da doença, o momento em que ela mostra a sua cara, e em nossa sociedade existe certa "tolerância” à loucura, quando esta se apresenta "controlada", "amansada". Porém, quando a loucura mostra sua face "enraivecida" (crise) a sociedade ainda impõe como castigo sua reclusão e dominação, e o lugar reconhecido socialmente como capaz de estabelecer essa relação de poder/força é o manicômio (KINOSHITA, 2008).

Assim, a crise, nos dias de hoje, sustenta o sentido de medo e perigo que acompanha a loucura desde seus primórdios, além de ser o momento em que a 
sociedade reconhece a loucura. O discurso científico sobre loucura, principalmente

em torno da crise psíquica- devido ao risco de atos violentos e agressivos - despertou na sociedade o sentimento de medo e trouxe para o cenário social a noção de periculosidade. Em nome deste perigo e, para garantir a ordem social, o louco teve seus direitos civis, sociais e políticos negados e sua liberdade sequestrada.

No modelo clássico da psiquiatria, a crise é entendida como uma situação na qual há uma grave disfunção, e ocorre exclusivamente em decorrência da doença (AMARANTE, 2007). Já no contexto da saúde mental, a crise é concebida como a expressão de uma crise existencial, social e familiar, que envolve a capacidade subjetiva do sujeito em responder a situações desencadeantes (BASAGLIA, 1979), sendo considerada uma situação mais social do que biológica ou psicológica (AMARANTE, 2007). Neste sentido, é necessário que haja, nos serviços de atenção psicossocial, a "responsabilização" por parte das pessoas que estão sendo cuidadas, a partir do acolhimento da crise e da construção de vínculos afetivos e profissionais com estas pessoas (AMARANTE, 2007). A crise precisa ser vista como uma possibilidade de transformação da relação entre profissional e usuário e do usuário com a sociedade. Por isso, consideramos de extrema importância compreender, a partir das práticas discursivas, os sentidos que os profissionais dos serviços substitutivos estão atribuindo à "crise".

"Dar sentido ao mundo" é uma atividade tipicamente humana. É um processo de construção social, de interação intersubjetiva, no qual os sujeitos, a partir de suas práticas discursivas, posicionam-se, reconhecem-se e constroem os termos para a compreensão dos eventos cotidianos (SPINK; FREZZA, 2000; SPINK; MEDRADO, 2000).

Por possuirmos o entendimento de que a sociedade, tanto na Antiguidade como nos dias de hoje, possui um limiar de tolerância menor quando o sujeito em sofrimento psíquico expressa agressividade, este estudo tem o objetivo de entender os sentidos presentes nas práticas discursivas dos profissionais de serviços substitutivos referentes à atenção à crise psíquica grave com comportamento agressivo.

\section{Metodologia}

Por entendermos que o cotidiano de trabalho nos serviços substitutivos de saúde mental gera novos sentidos e formas de conhecimento acerca da loucura, escolhemos 
o construcionismo social, enquanto perspectiva teórica, para a compreensão dos novos sentidos que estão sendo construídos no dia a dia destes serviços.

A investigação construcionista preocupa-se com a explicitação dos processos pelos quais as pessoas, através da linguagem, descrevem e explicam o mundo em que vivem (SPINK; MEDRADO, 2000). Isso implica adotar que o conhecimento é algo que as pessoas produzem juntas, a partir de correspondências histórica e culturalmente situadas, como resultado da socialização do conhecimento e não de algo que se apreende do mundo ou de processos internos da mente. Portanto, consideramos que a análise das práticas discursivas dos profissionais é uma forma privilegiada para entendermos os sentidos atribuídos à crise e como esses sentidos influenciam no cuidado prestado e no lugar que cada um, profissional e usuário, ocupam na relação.

Os dados utilizados fazem parte do banco de dados da pesquisa Avaliação dos Centros de Atenção Psicossocial da Região Sul do Brasil (CAPSUL), que se dividiu em dois estudos, um quantitativo e outro qualitativo. A avaliação qualitativa concentrou-se em Centros de Atenção Psicossocial I e II de cinco municípios da Regiāo Sul do país: Alegrete, Joinville, São Lourenço do Sul, Porto Alegre e Foz do Iguaçu.

Desenvolvida na forma de estudo de caso, a pesquisa ${ }^{1}$ contou com a participação de usuários, familiares e profissionais e a avaliação de quarta geração (GUBA; LINCOLN, 1989; WETZEL, 2005) norteou o processo teórico-metodológico. $\mathrm{O}$ projeto de pesquisa foi apreciado e aprovado pelo Comitê de Ética e Pesquisa da Faculdade de Medicina da Universidade Federal de Pelotas (Of. 074/05, de 11 de novembro de 2005). Todos os entrevistados concordaram em participar da pesquisa mediante a assinatura de consentimento livre e esclarecido.

A coleta de dados ocorreu de julho a dezembro de 2006, tendo a duração de quatro semanas em cada município. Para tanto, utilizaram-se a observação de campo e a entrevista semiestruturada, inicialmente composta por três questóes norteadoras, sendo que novas perguntas foram incorporadas através da utilização do circulo hermenêutico-dialético, num processo concomitante de análise e coleta dos dados (GUBA; LINCOLN, 1989).

Neste estudo, foram analisadas as entrevistas dos 27 profissionais do Centro de Atenção Psicossocial (CAPS) do município de Alegrete. O critério adotado na seleção dos sujeitos foi possuir vínculo empregatício com o serviço. Assim, todos 
os profissionais (enfermeiro, assistente social, psicólogo, professor de educação

física, técnico de enfermagem, pessoal da recepção, da portaria e da limpeza, dentre outros) foram entrevistados. Após a leitura das entrevistas, identificamos os repertórios interpretativos (SPINK; LIMA, 2000), que são unidades de construção das práticas discursivas, buscando identificar os temas mais relevantes e as categorias analíticas que respondessem ao objetivo proposto no estudo. Logo após construímos os mapas de associação de ideia (SPINK; LIMA, 2000), enquanto instrumentos de visualização que têm por objetivo auxiliar na sistematização do processo de análise das práticas discursivas, buscando os aspectos formais da construção linguística, dos repertórios utilizados e a dialogia implícita na produção de sentidos.

Assim, a análise dos dados ocorreu mediante o entrelaçamento de quatro aspectos: os repertórios interpretativos e mapas de associação de ideias, a literatura investigada durante a pesquisa, a perspectiva teórico-metodológica e a interpretação das pesquisadoras, identificando nas práticas discursivas os sentidos que envolvem a crise.

\section{Resultados e discussão}

Este estudo procura mostrar como os sentidos que envolvem a crise foram construídos enquanto verdades, fabricados nos jogos de saber-poder expressos a partir do processo de interação entre as pessoas que, ao se expressarem discursivamente, posicionam-se a favor ou contra o poder hegemônico.

A crise tornou-se um entrave, pois é ela que, nos dias de hoje, sustenta o sentido de medo e perigo que acompanhou a loucura por muito tempo. Com a revolução dos psicofármacos, passou-se a ter a possibilidade de dominar a loucura fora dos muros do manicômio e, assim, o que passou a incomodar a comunidade e a família são as crises, pois quebravam a normalidade do cotidiano (JARDIM; DIMENSTEIN, 2007). A psiquiatria clássica reduziu o doente a sua doença, enquanto a crise, em toda a sua complexidade, foi reduzida e definida como simples agudização da sintomatologia (FERIGATO; CAMPOS; BALLARIN, 2007). Os sintomas característicos de uma crise descritos na literatura são: delírios, alucinações auditivas e visuais, agitação psicomotora, agressividade etc.

A agressividade e o comportamento violento constituem um dos desafios para a prática psiquiátrica (GOMES et al., 2008). O comportamento do louco, 
considerado pela psiquiatria como incompreensível e imprevisível, despertou certa dose de temor e justificou a adoção de práticas de exclusão e segregação orientadas pela ideia de que o louco é um ser perigoso para si e para seu grupo social (KANTORSKI; MIRON, 2001).

A ideia de periculosidade nasceu associada ao conceito de alienação mental e, em virtude de este conceito estar associado à perda da razão, à irracionalidade e à animalidade, contribuiu para a construção do sentido social de medo e para a discriminação com as pessoas identificadas como tal (AMARANTE, 2007). Nas falas apresentadas, emergem sentidos de medo em relação à crise:

Nós já tivemos muitos casos bem graves. Eu mesmo posso admitir que logo que eu comecei a trabalhar aqui, eu, primeiramente eu quase nem dormia direito em casa. Porque foi bem violento um surto que a gente pegou de um paciente que ele agrediu um brigadiano. O brigadiano levou 8 pontos no queixo, no lábio em tudo assim ó. Mas depois com o passar do tempo a gente vê que aquele medo, aquele receio que a gente tem do serviço é tudo bobagem. Mas a segurança, isso é bem verdade. [A2]

Percebemos na fala um discurso contraditório, pois o profissional diz que o medo passou, mas termina ressaltando a importância da segurança. Para desconstruir o sentido de periculosidade social que envolve as situações de crise, é necessário que os aspectos negativos da crise sejam redimensionados de maneira que seja construído o entendimento de a crise ser uma situação possível de ocorrer mesmo em casos nos quais a equipe considere que o usuário em questão tenha um bom acompanhamento terapêutico. Este entendimento é percebido na seguinte fala:

Eu entendo que vai ter isso de vez em quando, que por mais que a gente cuide da medicação, que a gente fale com a família. Quando tu vê às vezes tu diz: aí, eu não entendo, está bem medicado, está cuidadinho, a família não sei o que [...] Olha, tem surtos graves que eu acompanhei e que, quem entrou depois nunca viu, [...] Então assim, são surtos horrorosos. E assim, que assustam, muito agressivos e, que, bem tratadinhos não aconteceram mais. E alguns acontecem. [...] alguns que ainda acontecem e vão acontecer, sinceramente assim, eu acho normal. [A11]

Outro fato que chama a atenção nesta fala e que é fundamental para o cuidado à crise é o entendimento de que este não é apenas o momento agudo em que os sintomas predominam, mas é um momento complexo que envolve a existência do sujeito com suas questões familiares, sociais, de relação e de afeto. Por isso, para o cuidado da crise é necessário lançar mão de instrumentos complexos, como a escuta que permita a expressão das subjetividades e uma intervenção que instrumentalize o sujeito a responder as situações desencadeantes da crise. Pela fala, 
podemos apreender ainda que o serviço tem conseguido avanços com relação ao cuidado da crise, pois alguns usuários, conhecidos por suas crises muito agressivas, estão conseguindo construir recursos para responder às situações conflituosas.

$\mathrm{Na}$ Itália, o conceito de periculosidade foi abolido pela Lei $\mathrm{n}^{\circ} 180$, e colocado em seu lugar outro conceito: "que as organizações médicas e sociais respondam às necessidades reais do povo" (BASAGLIA, 1979, p. 89). Este conceito é importante, pois direciona as práticas de cuidado à crise para o sujeito em sua totalidade, transformando o ato terapêutico de integração que reabsorve a crise retrocedendo à aceitação daquilo que a provocara (BASAGLIA, 1985). No entanto, existem situações de intervenção na crise, ocorridas no CAPS de Alegrete, que deixam os profissionais com dúvidas sobre "esse fazer", como podemos observar nas falas a seguir:

Não vou te dizer que às vezes, sei lá, passa a semana, duas semanas e está sempre do mesmo jeito. Ai, será que eu estou fazendo, será que está certo. Às vezes eu vou para supervisão para vê isso. Não está andando, será que é culpa minha, mas assim, isso eu acho normal, né. Não é mais manicômio. A gente está cuidando aqui e, aí vão ter situações. Então claro, mas aí eu tenho plena consciência, vai ter aquele momento sim de crise. Alguns ainda vão ter. [A11]

O usuário (em crise). A gente vai ficar com o usuário aqui? Eu digo: para onde tu quer que a gente mande o usuário. Aí às vezes a gente tem que ser meio dura assim. $\mathrm{O}$ que? Nós vamos mandar o usuário para casa, para ele ser agredido, para ele agredir, para ele continuar usando mais droga do que ele já usa? Nós vamos mandar o usuário para um hospital psiquiátrico ou nós vamos ficar aqui estudando o caso dele para achar uma alternativa melhor para ele. [A3]

A desinstitucionalização - entendida não apenas como abertura das portas do manicômio, mas também como a abertura de nossas cabeças para o entendimento daqueles que nos procuram - faz com que se modifique a relação profissional/usuário, ou seja, o profissional não tem mais respostas institucionais prontas, mas deve criar alternativas concretas dentro da própria relação tensa, de sujeito a sujeito, entre aquele que procura o serviço e o técnico que recebe uma demanda (KINOSHITA, 1987).

No campo do cuidado à saúde, e mais especificamente na construção cotidiana de uma rede antimanicomial, há de se ter lado e poder falar dele. Ter lado é oferecer um trabalho vivo em ato, buscando produzir relações vivificadoras e um fazer compromissado com a construção de autonomias (MERHY, 2007). Essa questão nos remete a um aspecto importante que encontramos nas falas, pois 
mesmo os profissionais demonstrando dúvidas quanto ao fazer, percebemos um comprometimento em construir um modelo de cuidado diferente do manicômio, uma disponibilidade para buscar uma solução singular que cada caso exige, sendo este um importante indício da permanente reflexão e construção no campo da reforma psiquiátrica (AMARANTE, 2007).

A trajetória de intolerância e preconceito ligada ao louco fez do hospital psiquiátrico o emblema da exclusão e do sequestro da cidadania e, da vida dos sujeitos, um sofrimento. $\mathrm{O}$ estigma da periculosidade tem acompanhado o louco, trazendo como consequência o isolamento/asilamento e a negação de seus direitos de serem cuidados como cidadãos (LOBOSQUE, 1997). Esse sentido de periculosidade que sequestrou os direitos de cidadania do louco é encontrado ainda presente no imaginário social e no imaginário de alguns profissionais, como podemos observar nas falas:

Eu vejo que tem pessoas ainda, colegas nossos que tem medo. Eles tem medo assim. [A3]

Eu tenho experiência, já trabalhei no Hospital Psiquiátrico, e eu não me sentia tão insegura e aqui no serviço eu me sinto, principalmente na parte da tarde. [...] Que de manhã a gente tem um que é estagiário de, do setor x, que é uma pessoa, que dá assim um respaldo quando a gente tem uma situação difícil de lidar. E, e, assim, de tarde, a gente se sente meio desprotegida. [A16]

Não tem como a gente dizer que não fica insegura, a pessoa às vezes batendo boca e agredindo a gente verbalmente. Aquilo mexe, não tem como tu... Quando ela chegou com aquele pau assim na porta, eu digo pára aí que eu vou chamar a tua terapeuta. E oh, eu digo, eu não vou ficar naquele brete ali [...] Eu já perdi um irmão, eu tenho medo, eu não vou, não vou esperar de graça. Porque aquele pau quem é que contém? [A20]

Ah, é perigo. É risco de vida até. Porque tu vais entrar numa casa tu nunca imagina o que vai estar te esperando lá dentro. Eu já vi vários pacientes bem agressivos, a gente tem que dizer então tá, muito obrigada, e sair rapidinho. Eu acho que a gente sempre está com esse risco. Principalmente nas visitas domiciliares. Só que eu não sei o quê que a gente poderia fazer para evitar isso, sabe? [A23]

Nas falas emergem questôes importantes, como o medo sentido pelos profissionais de forma intensa. Podemos observá-lo quando estes relatam que correm "risco de vida", que "já perdeu um irmão e não vai esperar uma agressão de graça". Temer a crise, em nosso entendimento, reforça o sentido de exclusão, que se manifesta na forma de distanciamento entre o usuário e o profissional do serviço.

Para Maurício (1991, p. 9), temer a loucura serve apenas para justificar a violência que se emprega contra o louco e para validar os anteparos profissionais que nos separam irremediavelmente, como pessoas, do louco. Com medo, troca-se 
muito pouco, conhece-se pouco. Pode-se "ajudar", diagnosticar, "tratar", jamais

amar. Neste sentido, ressaltamos a importância de abrir não somente as portas do manicômio, mas nossas cabeças, para que se construa o entendimento que extinga a demanda convencional crise/internação no hospital psiquiátrico, urge incendiar o manicômio que existe dentro de cada operador, a lógica de exclusão que a prática pode perpetuar sem perceber (DELGADO, 1991, p. 17).

Outra questão que aparece na segunda fala é o caso de o profissional expressar que sente medo de trabalhar no CAPS, pois se sente desprotegido, o que não ocorria quando trabalhava no hospital psiquiátrico. Este fato acontece porque no manicômio os profissionais estão "respaldados" pelo aparato manicomial, trabalham implicitamente com a noção de periculosidade - "como um policial que deixasse sempre entrever o volume da arma sob o uniforme" (LOBOSQUE, 1997, p. 30). Essa noção justifica as "terapias” de cura do manicômio, propostas para impedir a possibilidade da pessoa exprimir-se como sujeito, tornando-a objeto. Nesses espaços, o grau de repressão é tão intenso que inibe o sujeito de exprimir sua própria agressividade (BASAGLIA, 1979).

Ignorar a complexidade do sofrimento, simplificando-o por meio da atenção ao sintoma, retira do sujeito a responsabilidade por sua vida, descontextualiza-o e rouba sua autonomia, além de desconsiderar a potencialidade da crise enquanto movimento de mudança e transformação (JARDIM; DIMENSTEIN, 2007). Assim, muitos profissionais esquecem a potência intrínseca de uma crise que oferece uma oportunidade de transformação e desvio, momento de metamorfose, de saída de um lugar historicamente dado para outro a ser reconstruído (FERIGATO; CAMPOS; BALLARIN, 2007). Desta maneira, é necessário questionar algumas concepções ainda existentes em nosso cotidiano que tendem a generalizar a crise, entendendo-a como um desvio da conduta normal, como um erro, como uma dificuldade de adaptação ou distúrbio. Buscando, com isso, construir formas de compreender as situações de crise em sua singularidade e em seu contexto existencial (COSTA, 2007).

Um importante passo para mudar a lógica da periculosidade, que insere a crise no contexto da exclusão, é devolver ao sujeito as condições para o desenvolvimento de sua cidadania, devolvendo-lhe a "responsabilidade e possibilidade de conviver e partilhar com os outros de uma mesma estrutura social e política" (AMARANTE, 2007, p. 34). 
O conceito de cidadania, defendido na reforma psiquiátrica, relaciona-se à ampliação dos direitos sociais, jurídicos e políticos dos sujeitos em sofrimento psíquico, assim como trata, sobretudo, da ampliação desse conceito no sentido de reconhecer a "pluralidade dos sujeitos, com suas diversidades e diferenças num mesmo patamar de sociabilidade. Trata-se, ainda, não de deixar o louco viver a sua loucura, porém de, em um novo contexto de cidadania, dar-lhe o real direito ao cuidado" (AMARANTE, 1997, p. 115). Cuidado que não exclua, violente ou discrimine os sujeitos, mas que construa possibilidades para a valorização de seus desejos e projetos.

No contexto atual, as situações de crise geram muitos conflitos e contradições nas relações entre profissionais e usuários. Podemos observar que, no cotidiano do CAPS de Alegrete, as situaçôes de crise despertam diferentes posicionamentos e sentidos, pois embora alguns profissionais tenham relatado sentir medo; outros se posicionam de maneira diferente, demonstram disponibilidade para o cuidado dos usuários em crise e relatam não ter medo, conforme podemos constatar nas falas:

Não (se sente exposta), porque aqui a gente tem muita [...], todos ajudam. Então quando um está, um usuário está em surto, geralmente todo mundo vem ajudar. [A7]

Eu já apanhei, já me correram, um já me defendeu. Mas eu não tenho medo dos usuários. [...] Então dão risada quando eu digo que tenho medo dos cachorros e não dos usuários. Eu chego, eu converso e é rara as vezes que eles me agridem. Então às vezes eu não entro de medo dos cachorros, que os cachorros vêm e avançam na gente, eu já fui mordida três vezes e tenho medo. Mas dos usuários eu não tenho medo nem aqui dentro. [A8]

Medo assim eu não tenho. Eu tento sair, porque às vezes eu até ajudo, [...] a pegar assim, sabe? Ele pra não machucar, pra até a Brigada chegar, para dar um remédio, sabe? Acalmar eles. Colocar eles para não quebrar, não se machucar ai dentro com vidro mesmo. Até ele escuta a gente quando o personagem 3 está assim. Medo, eu não tenho medo. [A14]

É necessário pensar na desproteção relativa com a qual se trabalha em um serviço aberto, como é o caso do CAPS, sem menosprezar a gravidade de uma crise. A construção de uma clínica desarmada não nega o risco que uma situação de crise pode acarretar, mas sobrepõe a este o compromisso de construir um cuidado em liberdade que respeite a diferença e, acima de tudo, retire o sujeito do isolamento e exclusão e coloque-o em espaços de vida e sociabilidade (DELGADO, 1991). Com esse entendimento, os profissionais poderão construir novas formas de abordagem do usuário em crise que não sejam atitudes de violência, repressão, 
nem de indiferença, pois muitas vezes o medo impede a aproximação, o vínculo e o sentido de responsabilização pelo cuidado na crise.

A primeira atitude para a organização de um cuidado humanizado à crise é a intervenção precoce baseada no diálogo empático e orientada nos aspectos emocionais e motores do usuário em crise. A abordagem inicial deve incluir, além de uma relação empática entre profissional e usuário, algumas preocupações para mudar o ambiente e torná-lo seguro para todos os presentes. Para isso, são necessárias algumas medidas, como atender prontamente a crise, escolher um ambiente calmo e sem estímulos intensos para a intervenção, manter uma postura calma e com tom de voz baixo, e retirar objetos que possam ser potencialmente perigosos (GOMES et al., 2008).

A preocupação com a organização de um ambiente seguro é uma questão abordada nesta fala:

Eu tenho essa ideia, eu me preocupo com a segurança, tem o guarda que me deixa o cacetete ali em cima dos armários de aço, vivo pedindo para tirar. Porque eu acho que a gente não tem nem que botar tranca e nem deixar a faca na mão [...] sugerir uma situação que exponha a pessoa lá. E ali entram os usuários, circulam ali e tal. [A4]

Nas próximas falas, os profissionais abordam a questão da prevenção, no sentido de organizar a intervenção nas situações de crise de modo que o risco de agressão seja diminuído. Assim, é colocada a necessidade de, no mínimo, dois profissionais para a realização do manejo, e no caso de situações nas quais não é possível uma intervenção, que o profissional não se exponha.

Para prevenir situações que a gente considera assim. Por exemplo, a usuária aquele dia podia ter me dado um bofetão. Na hora eu disse: ela vai me dar [...] eu sempre digo: gente, se vocês sentirem o perigo saiam de perto. Se não tem como conter, se não tem como lutar, quebram carro, quebram isso, quebram tudo, mas não deixem agredir vocês. [A3]

Quando é muito assim, arriscado, eu não vou sozinha. Porque olha... os casos assim, que eu não estou conseguindo fazer grupo, que está muito nervoso, que ele está vendo alguém em mim, enfim, eu procuro compartilhar isso com algum dos colegas. Porque daí se precisar manejar a gente maneja de dois, é melhor que manejar de um. [A6]

Eu acho que é só com cautela. Nunca ir sozinha, quando vê que há um risco de perigo sempre levar mais alguém. [A23]

Com relação à primeira fala, cabe ressaltar que embora haja uma real necessidade de o profissional se preservar, ele não pode esquecer que o sujeito em crise também precisa de proteção e que a responsabilidade por essa proteção 
faz parte das funções dos trabalhadores do CAPS. Portanto, em casos nos quais não é possível fazer uma intervenção, o profissional precisa observar a situação e esperar um momento no qual o sujeito em crise esteja mais acessível a uma intervenção ou um momento em que haja maiores recursos para a abordagem. Contudo, não podemos nos afastar do entendimento de que pessoas em crise "precisam de ajuda e, em casos extremos essa ajuda precisa ser imediata", pois o que está em jogo é a imprevisibilidade (JARDIM; DIMENSTEIN, 2007, p. 183). Assim, é importante preservarmos a ideia de urgência enquanto cuidado que pode ser prestado imediatamente, ou seja, um tipo de "atenção urgente à pessoa em crise", para com isso desconstruir a ideia de urgência psiquiátrica que reforça a loucura como doença mental, trazendo consigo toda sua história de violência e estigma (JARDIM; DIMENSTEIN, 2007).

Nas falas seguintes, é comentada a importância de haver dois profissionais para o manejo da crise e de se compartilhar com os colegas de equipe quando um usuário começa a apresentar alucinações e delírios de referência em relação a algum profissional, por exemplo, a fala "tá vendo alguém em mim”, indicando que este alguém pode de alguma forma ameaçá-lo. Isto demonstra a necessidade de se manter uma relação terapêutica com o usuário buscando a aproximação, a presença e a disponibilidade da equipe para entrar em relação e lidar com os conflitos, buscando construir "novas possibilidades de interação com o sofrimento psíquico, abrindo brechas na construção cultural da ausência de valor do louco e no imaginário da periculosidade" (NICÁCIO; CAMPOS, 2004, p. 75).

Portanto, os Centros de Atenção Psicossocial (CAPS), por serem serviços substitutivos e por prometerem ser o lugar de críticas às formas hegemônicas de se construir práticas de saúde e de construção de práticas antimanicomiais, estão no "olho do furacão antimanicomial". E isso os torna lugares para manifestação de grandes conflitos e desafios, e "ousar dar conta dessas missões gigantescas, é estar aberto a operar no tamanho da sua potência e governabilidade" (MERHY, 2007, p. 56).

Construir um cuidado antimanicomial, estando no "olho do furacão", é poder usufruir das dúvidas e das experimentações. Seria muito importante tomar isso como um "elemento positivo, como marcador contra os que possam imaginar que o CAPS já é o lugar das certezas antimanicomiais", pois a postura de seguir modelos fechados ou receitas prontas elimina a interessante multiplicidade deste, 
comprometendo o aproveitamento desse fazer coletivo, solidário e com grande potencial experimental (MERHY, 2007, p. 57).

Desse modo, entendemos que a intervenção no momento de crise pode gerar, em muitas situações, angústia nos profissionais mobilizando sentidos de impotência a partir da experiência do não-saber. Essa situação é relatada na fala que segue:

Eu tento lidar da melhor maneira. Às vezes a gente não raciocina, às vezes as coisas que tu vai vê, parece que o corpo que está tremendo. Que tu não tem tempo de codificar e decodificar o pensamento, mas às vezes, parece que é irresponsabilidade nossa não conseguir pegar, tomar o pau daqueles da mão de um usuário. [A20]

Numa situação de crise, o profissional precisa usar sua clínica e perspicácia para acolher, escutar, expor-se a vínculos e jogos transferenciais - enfim, gerar intervençôes singulares e aproveitar a oportunidade que a crise oferece para ressignificar o projeto terapêutico do usuário (MERHY, 2007). O cuidado da crise em liberdade, pautado numa relação de contratualidade em que o outro é considerado um sujeito de direitos e de poder, não possui respostas prontas. Por ser a crise um momento singular, o cuidado exige a intervenção num campo conflitivo e a construção de relação com usuários, "singularizando e contextualizando o campo de possibilidades e de significados no qual se inscrevem" (NICÁCIO; CAMPOS, 2004, p. 76).

Por conseguinte, a atenção à crise precisa romper com o sentido de periculosidade que coloca o louco como ameaçador, do qual devemos nos proteger. A periculosidade é um critério generalizante usado para exclusão e segregação da loucura sem nenhuma contribuição no desenvolvimento da escuta. É ainda um critério inadequado, "porque não leva em conta que todo o sujeito - mesmo os considerados 'normais' - pode ter atitudes imprevisíveis e incompreensíveis" (KANTORSKI; MIRON, 2001, p. 16). Assim, a imprevisibilidade é componente da natureza humana e não está limitada à loucura, embora esta carregue o sentido de medo e a necessidade de distanciamento social.

Esse entendimento, de que a crise é uma situação que pode acontecer e que o risco e da insegurança que ela envolve não são diferentes do risco e da insegurança a que estamos expostos no dia a dia, surge nas falas de alguns profissionais.

Eu acho que o risco que a gente corre aqui não é diferente do que a gente corre no geral. Acho que um pouco do bom senso nas coisas, vale a pena. É de preocupar? É. Porque é a vida da gente. Mas não acho que seja o ponto, o nó crítico do serviço [...] Eu acho que tem uma certa preocupação nossa que é próprio da clientela que a gente está. Então tem épocas que essa preocupação cresce um pouco mais, dependendo se 
teve alguma intercorrência maior ou não. Eu não acho que seja um nó, [...] aqueles que já tão aqui que a gente já sabe mais ou menos quem são os mais difíceis de abordar em surto. O nosso maior desafio é para aqueles que a gente não conhece. [A5]

O que eu penso sobre isso [...] eu acho que é normal. Eu acho que isso é uma coisa inerente ao nosso trabalho [...] se a gente não quiser encarcerar é assim. Então assim, pra mim, eu não acho uma coisa absurda, pra mim é natural. [A11]

Um fato que chama atenção na primeira fala é de o profissional reconhecer que o cuidado à crise não é o nó do serviço. Concordamos com isto, mas entendemos que o tema "cuidado à crise" precisa ser discutido cotidianamente para que possamos compreender os sentidos que a envolvem e o posicionamento, tanto nosso quanto das pessoas que compõem o cotidiano, em relação a ela. Somente a partir deste entendimento poderemos discutir formas de lidar com a crise sem receios e tabus.

Outra questão relatada na fala diz respeito à dificuldade de cuidar da crise em casos nos quais não se conhece o usuário. Este se constitui como um dos desafios do cuidado à crise, pois, conforme a discussão que viemos fazendo, entendemos que o vínculo é uma potente ferramenta para o cuidar no momento em que os sintomas se agudizam e as pessoas necessitam ainda mais de laços afetivos. No entanto, consideramos que o primeiro encontro entre profissional e usuário, mesmo que este esteja em crise, é o momento de construir as bases para uma relação de confiança, vínculo e reciprocidade.

$\mathrm{Na}$ segunda fala, o profissional reconhece o desafio de cuidar da crise em liberdade, porém demonstra uma atitude, uma posição de responsabilização por esse cuidado, a partir do entendimento de que, para mudar a lógica do "encarceramento", precisamos encarar os desafios e construir formas de convivência com a loucura, inclusive nos momentos de crise.

Para restituirmos a cidadania roubada do sujeito em sofrimento psíquico, é necessário algo mais profundo do que mudanças administrativas e legais, ou seja, é uma nova construção social/cultural para um novo objeto, que não é mais a doença mental ou os sintomas da crise, mas o sujeito em suas singularidades. Compreender que a cidadania é um projeto aberto a ser construído cotidianamente, a partir da convivência com os diferentes e suas diferenças nos modos de responder à crise e às situaçôes desencadeantes. Isto permite construir novos sentidos para a loucura e para a crise, que não seja de exclusão, mas firmados numa postura ética e solidária. 
Segundo Foucault (2006, p. 36), "a doença mental foi construída pelo conjunto do que foi dito no grupo de todos os enunciados que a descreviam, explicavam, contavam seus desenvolvimentos". Portanto, a desinstitucionalização da crise significa a reconstrução de sentidos, intercâmbio de novos papéis, transformação do modo como os doentes vivem e se relacionam com o seu próprio sofrimento e com a sociedade. No lugar dos sentidos de perigoso e incapaz, precisamos estudar possibilidades para o fortalecimento das capacidades dos sujeitos e para a inserção no corpo social, a partir da construção de práticas de atenção que respeitam e garantam os direitos de cidadania.

\section{Considerações finais}

A atenção à crise é um compromisso que torna a desinstitucionalização "mais real"; é uma luta cotidiana pela garantia do direito à singularidade, à subjetividade e à diferença; é a negação dos sentidos de periculosidade que coloca o louco como uma ameaça à sociedade; é a construção de práticas discursivas, posicionamentos e práticas de cuidado capazes de produzir novos sentidos, nos quais as pessoas em sofrimento psíquico sejam reconhecidos como sujeitos de direito.

A experiência de atenção à crise desenvolvida no Centro de Atenção Psicossocial de Alegrete, apreendida neste estudo, demonstrou que há uma "tomada de responsabilidade pelo território", ou seja, existe um sentido de responsabilização pelas situações de crise que ocorrem no município. Esse serviço demonstrou ser um espaço territorializado, aberto e capaz de atender às urgências e acolher os usuários em crise.

No entanto, encontramos sentidos de medo em relação à crise. E gostaríamos de, aqui mais uma vez, ressaltar que o medo do louco e da loucura é um sentido que impossibilita à construção de uma relação sujeito-sujeito, de um encontro em que estejam presentes o vínculo, a afetividade e a reciprocidade. Ao temer o louco, não permitimos que ele seja sujeito de sua própria história e nos negamos à possibilidade de conviver e compartilhar, com ele, o momento de sua crise. Assim, precisamos de disponibilidade afetiva para conviver e para caminharmos junto ao outro, respeitando suas decisões e seu tempo.

Portanto, esperamos que este estudo contribua para a reflexão acerca dos nossos fazeres em relação à crise e os sentidos que nossas práticas discursivas e posicionamentos estão cotidianamente construindo. Nós, profissionais de saúde 
mental, podemos ser amarras que isolam e castigam ou laços que sustentam e acolhem, isso só depende da nossa construção cotidiana.

\section{Referências}

TERRA, M.G. et al. Saúde mental: do velho ao novo paradigma - uma reflexão. Esc. Anna Nery. Rio de Janeiro, v. 10, n. 4, 2006.

AMARANTE P. Saúde mental e atenção psicossocial. São Paulo: Fiocruz, 2007. 117p.

AMARANTE, P. Loucura, cultura e subjetividade: conceitos e estratégias, percursos e atores da Reforma Psiquiátrica. In: FLEURY, S(Org.). Saúde e democracia: a luta do CEBES. São Paulo: Lemos Editorial, 1997.

BASAGLIA, F. A instituição negada: relato de um hospital psiquiátrico. 1ed. Rio de Janeiro: Graal, 1985.

BASAGLIA, F. A Psiquiatria alternativa: contra o pessimismo da razão o otimismo da prática. Conferências no Brasil. São Paulo: Brasil Debates, 1979.

COSTA, M.S. Construções em torno da crise: saberes e práticas na atenção em saúde mental e produção de subjetividades. Archivos Brasileiros de Psicologia, Rio de Janeiro, v. 59, n. 1, p. 94-108, 2007.

COSTA-ROSA, A.; LUZIO, C.A.; YASUI S. As conferências nacionais de saúde mental e as premissas do modo psicossocial. Saúde em Debate, Rio de Janeiro, v. 25, n. 58, p. 12-25, maio/ago. 2003.

DELGADO, J. Reflexões na cidade sem manicômios. In: DELGADO J (Org.). A loucura na sala de jantar. São Paulo: Resenha, 1991.

FERIGATO, S.H.; CAMPOS, R.O.; BALLARIN, M.L. O atendimento à crise em saúde mental: ampliando conceitos. Rev de Psicologia da UNESP, v. 6, n. 1, p. 31-44, 2007.

FOUCAULT, M. A arqueologia do saber. Rio de Janeiro: Forense Universitária, 2006.

GOMES, F.A. et al. Agressividade e agitação psicomotora. In: QUEVEDO, J.; SCHMITT, R.; KAPCZINSKI, F. Emergências psiquiátricas. Porto Alegre: Artmed, 2008. p. 109-124.

GUBA, E.; LINCOLN, Y. Effective evalution. SanFrancisco: Jossey Bass, 1998.

JARDIM, K.; DIMENSTEIN, M. Risco e crise: pensando os pilares da urgência psiquiátrica. Psicologia em Revista. Belo Horizonte, v. 13, n. 1, p. 169-190, 2007.

KANTORSKI, L.P.; MIRON, V.L. A periculosidade silenciada: aportes para pensar a ética nos serviços de saúde mental. Rev URCAMP, Bagé/RS, v. 5, n. 2, p. 13-20, 2001.

KINOSHITA, R.T. O cuidado da crise nos Centros de Atenção Psicossocial. Aula aberta do Curso de Especialização em Atenção Psicossocial no Âmbito do SUS, Pelotas, 2008. 
KINOSHITA, R.T. Uma experiência pioneira. A reforma psqiuiátrica. In: MARSAGLIA,

R.G. Saúde mental e cidadania: Plenário de Trabalhadores de Saúde Mental do Estado de São Paulo. 2.ed. São Paulo: Mandacaru, 1987. p. 67-83.

LOBOSQUE, A.M. Princípios para uma clínica antimanicomial e outros escritos. São Paulo: Hucitec, 1997.

MAURÍCIO, J. Apresentação. In: DELGADO, J. (Org.). A loucura na sala de jantar. São Paulo: Resenha, 1991.

MERHY, E.E. Os CAPS e seus trabalhadores: no olho do furacão antimanicomial. Alegria e alívio como dispositivos analisadores. In: MERHY, E.E.; AMARAL, H (Org.). A reforma psiquiátrica no cotidiano II. São Paulo: Aderaldo \& Rothschild, 2007. p. 55-66.

NICÁCIO, F.; CAMPOS, G.W.S. A complexidade da atenção às situações de crise - contribuições da desinstitucionalização para a invenção de práticas inovadoras em saúde mental. Rev. Ter. Ocup. Univ. São Paulo, v. 15, n. 2, p. 71-81, mai./ago., 2004.

SPINK, M.J.; FREZZA, R.M. Práticas discursivas e produção de sentidos: a perspectiva da psicologia social. In: SPINK, M.J. (Org.). Práticas discursivas e produção de sentido no cotidiano: aproximações teóricas e metodológicas. São Paulo: Cortez, 2000. p. 17-39.

SPINK, M.J.; MEDRADO, B. Produção de sentidos no cotidiano: uma abordagem teórico-metodológica para análise das práticas discursivas In: SPINK, M.J. (Org.). Práticas discursivas e produção de sentido no cotidiano: aproximações teóricas e metodológicas. São Paulo: Cortez, 2000. p. 41-61.

WETZEL, C. Avaliação de serviços de saúde mental: a construção de um processo participativo Tese (Doutorado em Enfermagem) - Escola de Enfermagem da Universidade de São Paulo, Ribeirão Preto, 2005.

SPINK, M.J.; LIMA, H. Rigor e visibilidade: a explicação dos passos da interpretação. In: SPINK, M.J. (Org.). Práticas discursivas e produção de sentido no cotidiano: aproximações teóricas e metodológicas. São Paulo: Cortez, 2000. p. 9-16.

\section{Nota}

${ }^{1}$ Agradecimentos: à CAPES e ao CNPq. 
Periculosity and citizenship: the meanings of attention to the crisis in the discursive practices of the Psychosocial Healthcare Centers professionals

The crisis, considered the expression of mental illness, refers to situations in which, during the development of life, there are conflicting experiences that generate ruptures with the socially accepted reality and the emotional ties that sustain the person. This study aims at getting to know the meanings present in the discursive practices of professionals concerning the attention to the crisis in the Psychosocial Healthcare Centers (CAPS). It is characterized by a qualitative approach that uses the theoretical perspective of social constructionism. The data used are part of the database research Evaluation of Psychosocial Healthcare Centers in Southern part of Brazil - CAPSUL. In this study, 27 interviews with professionals from the Psychosocial Healthcare Center of Alegrete city and three field diaries with the record of 390 observation hours were analyzed. Data analysis identified the meanings - periculosity and citizenship - which were discussed in an attempt to understand their influence on the construction of attention practices to the crisis.

> Key words: Crisis intervention; psychiatric nursing; mental health; production of meaning. 